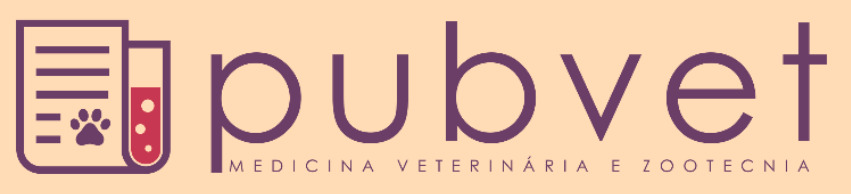

https://doi.org/10.31533/pubvet.v13n12a475.1-8

\title{
Importância dos aspectos biométricos na seleção de reprodutores bovinos: revisão
}

\author{
Karolayne Alves Mendonça ${ }^{1}{ }^{\bullet}$, Jessica Rosa Figueiredo ${ }^{1}{ }^{\bullet}$, Lorrany de Melo Santos ${ }^{1}{ }^{\bullet}$, Maisy Cordeiro \\ da Silva ${ }^{1}$, Daniela Menezes da Cruz ${ }^{1}$, Rodrigo Cruz de Freitas Lima ${ }^{1}$, ,Marlon de Araújo Castelo Branco ${ }^{2} \odot$ \\ ,Leopoldina Almeida Gomes ${ }^{3}{ }^{\circ}$, Isolda Márcia Rocha do Nascimento ${ }^{4}{ }^{\circ}$, Kalina Maria de Medeiros Gomes \\ Simplício $^{50}$, Paula Regina Barros de Lima ${ }^{50}$, Yndyra Nayan Teixeira Carvalho Castelo Branco ${ }^{5 *} \bullet$ \\ ${ }^{1}$ Graduando da Universidade Federal de Sergipe - UFS, Núcleo de Medicina Veterinária, Nossa Senhora da Glória - SE Brasil. \\ ${ }^{2}$ Professor da Faculdade Maurício de Nassau - UNINASSAU, Teresina - PI Brasil. \\ ${ }^{3}$ Professora do Instituto Múltiplo de Ensino - IESM, Departamento de Zootecnia, Timon - MA Brasil. \\ ${ }^{4}$ Professora do Colégio Técnico de Teresina - CTT, Teresina, PI Brasil. \\ ${ }^{5}$ Professora da Universidade Federal de Sergipe - UFS, Núcleo de Medicina Veterinária, Nossa Senhora da Glória - SE Brasil. \\ * Autor para correspondência, E-mail: yndyranayan1@hotmail.com
}

Resumo. O testículo é um órgão que possui função exócrina, relacionada com a produção, armazenamento e transporte de espermatozoides, e função endócrina relacionada com a produção de hormônios andrógenos. Na busca por bons reprodutores tem sido avaliado características morfometrias testiculares como a circunferência escrotal, no entanto, somente a mesma não é suficiente para realizar uma seleção, utilizando-se assim de outros parâmetros como volume e comprimento testicular. Tendo isso em vista, o objetivo desta revisão é abordar a influência dos fatores biométricos e sua relação com a morfologia testicular e a qualidade seminal, para a avaliação de reprodutores.

Palavras-chave: andrologia, eficiência reprodutiva, ruminantes, sêmen

\section{Importance of biometric aspects in breeding selection: review}

Abstract. The testis is an organ that has exocrine function related to sperm production, storage and transport, and endocrine function related to androgen hormone production. In the search for good breeders, testicular morphometric characteristics such as scrotal circumference have been evaluated, however, it is not enough to make a selection, using other parameters such as volume and testicular length. With this in mind, the aim of this review is to address the influence of biometric factors and their relationship with testicular morphology and seminal quality for breeding evaluation.

Keywords: andrology, reproductive efficiency, ruminants, semen

\section{Importancia de los aspectos biométricos en la selección de reproductores bovinos: revision}

Resumen. El testículo es un órgano que tiene una función exocrina relacionada con la producción, almacenamiento y transporte de esperma, y una función endocrina relacionada con la producción de hormonas andrógenas. En la búsqueda de buenos reproductores, se han evaluado las características morfométricas testiculares como la circunferencia escrotal, sin embargo, ésta no es suficiente para hacer una selección, utilizando otros parámetros como el volumen y la longitud testicular. Con esto en mente, el objetivo de esta revisión es 
abordar la influencia de los factores biométricos y su relación con la morfología testicular y la calidad seminal para la evaluación de la reproducción.

Palabras clave: andrología, eficiencia reproductiva, rumiantes, semen

\section{Introdução}

Os testículos são órgãos com função endócrina e exócrina, desempenhando suas funções mediante a produção de hormônios andrógenos como a testosterona, além de exercer papel na produção, armazenamento e transporte de espermatozoides. Morfologicamente os testículos são subdivididos em compartimentos intertubulares, composto por células somáticas, células de sertoli e leydig, e as células germinativas, que darão origem aos espermatozoides (Murta et al., 2019). A avaliação da caracterização das células de sertoli nas espécies domésticas, permite inferir que estas estarão em proliferação até a fase prépuberal, parando após a puberdade, próximo ao período de desenvolvimento da barreira das células de sertoli (França et al., 2000). Esta expressão celular está intimamente relacionada com os padrões morfológicos e biométricos da avaliação testicular, em animais pós púberes, capaz de depreender características produtivas de um macho no processo de seleção para a reprodução.

As medidas biométricas testiculares apresentam alta repetibilidade, correlacionando-se com a libido, qualidade do sêmen dos machos, peso corporal, dentre outras características produtivas e reprodutivas, além de serem obtidas facilmente (Quirino \& Bergmann, 1999; Vásquez et al., 2003).

De acordo com Unanian et al. (2000) no processo de seleção de reprodutores constam várias características morfo-fisiológicas do aparelho reprodutor, como as avaliações de circunferência escrotal e as seminais. Como parâmetros de escolha de reprodutores, algumas características têm sido introduzidas nestas análises, como o volume testicular e a forma dos testículos (Bailey et al., 1996; Unanian et al., 2000).

Segundo Silva et al. (2002) a circunferência escrotal é o parâmetro mais utilizado para seleção de reprodutores, devido á facilidade na mensuração e a relação com os parâmetros espermáticos, ademais apresenta correlação genética com outras características reprodutivas e com o peso corporal em diferentes idades. Entretanto, alguns autores discutem que a circunferência escrotal unicamente, não é uma medida preditiva da produção espermática, não sendo determinante para a avaliação do potencial reprodutivo dos machos. Testículos mais longos, como frequentemente encontrados nas raças zebuínas, apresentam maior superfície de contato com o meio ambiente, o que facilita a termorregulação, por apresentarem melhor distribuição dos vasos sanguíneos e tecido espermático mais uniforme, melhorando as características seminais (Bailey et al., 1996).

Fatores como a sazonalidade, efeito nutricional, representada pela disponibilidade alimentar influi no crescimento e na proporção testicular, e fatores como precipitação pluviométrica e temperatura sugerem alterações nos parâmetros morfológicos e biométricos dos testículos (Godfrey et al., 1990; Silva et al., 1991).

Tendo isso em vista, o objetivo desta revisão é abordar a influência dos fatores biométricos, sua relação com a morfologia testicular e a qualidade seminal, para a avaliação de reprodutores.

\section{Anatomia testicular}

Durante o desenvolvimento testicular as células de sertoli originam-se do epitélio celomático e são capazes de expressar genes determinantes para o surgimento do sexo masculino, como o gene SRY, desempenhando importante papel no direcionamento da diferenciação testicular (Combes et al., 2009).

O sistema neuroendócrino é peça fundamental para o controle das funções do sistema reprodutivo. Os testículos, órgão central do sistema reprodutivo masculino, irão executar suas atividades mediante o comando do eixo hipotalâmico-hipofisário-gonadal, uma vez que estas respostas induzem ação das gonadotrofinas, FSH e LH, sobre as células de sertoli e leydig para o desenvolvimento das células germinativas e controle da esteirodogênese, dentro e fora dos túbulos seminíferos (Cunningham, 2011; Kolb, 1984). 
Nos mamíferos domésticos, os testículos situam-se no escroto, cuja função é proteger as gônadas masculinas e auxiliar no controle da termorregulação, através da manutenção do fluxo sanguíneo, trocas calóricas e sudorese (Kastelic et al., 1997).

Em ruminantes, as características gerais, anatômicas testiculares, como contorno alongado e oval, eixo longo e vertical, borda inserida caudalmente, e superfície medial levemente achatada, permite um controle, em situações fisiológicas, da manutenção da qualidade espermática (Sisson et al., 1986).

\section{Descida dos testículos}

Em alguns mamíferos, os testículos se acomodam no escroto durante a vida fetal ou logo no início da vida pós-natal. $\mathrm{O}$ ambiente escrotal permite uma adequação das funções testiculares, como a espermatogênese, por apresentarem baixas temperaturas, situando-se de 4 a $6^{\circ} \mathrm{C}$ menores que a temperatura corporal (Dukes et al., 2006). A descida testicular é direcionada pelo gubernáculo, estrutura mesenquimal, que se estende do pólo caudal do testículo até a área inguinal (Sisson et al., 1986). O gubernáculo cresce em comprimento e diâmetro, expandindo-se para além do canal inguinal. Posteriormente ocorre um retrocesso, acomodando os testículos dentro do processo vaginal. Então com o aumento da pressão intra-abdominal e da tração do gubernáculo os testículos migram para a região inguinal (Köning \& Liebich, 2011). Entretanto, algumas desordens resultantes da exposição a xenobióticos, podem ocasionar anomalia urogenital congênita, prejudicando a dinâmica da migração testicular durante o desenvolvimento embrionário (Hutson et al., 2015; Skakkebaek et al., 2016; Virtanen \& Adamsson, 2012). Endocrinologicamente, a descida testicular nos mamíferos é mediada pelo fator anti-Mulleriana e pelos hormônios Ins13 e andrógenos, secretado pelas células somáticas, de sertoli e leydig, respectivamente (Hutson et al., 2013).

Além dos fatores mecânicos e endócrinos, outros fatores podem intervir na descida testicular, como a nutrição materna ao longo do período gestacional e início da lactação, podendo interferir inclusive nos mecanismos endócrinos, alteração na idade da puberdade, redução do peso, alterações morfofuncionais nos testículos, e alteração na contagem de espermatozoides e na taxa de fertilidade (Genovese et al., 2010). A restrição proteica, nesta mesma fase, pode induzir atraso na descida testicular em 4,4 dias (Zambrano et al., 2005).

\section{Componentes testiculares}

Superficialmente, os testículos são revestidos pela túnica albugínea, constituídos por fibras colágenas contendo vasos sanguíneos. Outro componente testicular é a túnica vaginal, que se sobrepõe a túnica albugínea conferindo uma aparência lisa da superfície testicular (Köning \& Liebich, 2011). Internamente, o parênquima testicular é constituído de túbulos seminíferos e tecido intersticial (O'donnel et al., 2001). Externamente aos túbulos seminíferos, o parênquima testicular é composto por compartimentos vasculares e intersticiais, e internamente, pelos compartimentos basais e adluminais (Dukes et al., 2006). Os túbulos seminíferos se contorcem da periferia a região central do testículo, abrindo em uma rede de túbulos confluentes dentro do mediastino ou também chamada de rete testis (Köning \& Liebich, 2011).

Os tipos celulares presentes no epitélio seminífero na vida fetal e pós-natal são as células somáticas, células de sertoli e leydig e as células germinativas, as precursoras dos espermatozoides. As células de sertoli estão localizadas ao longo dos túbulos seminíferos, separados das células de leydig pela barreira hematotesticular, que estão localizadas no espaço intersticial. O desenvolvimento destas células ocorre na maior parte das espécies ao longo do desenvolvimento fetal, sofrendo ação das gonadotrofinas, as quais respondem ao eixo hipotalâmico-hipofisário-gonadal. E na maioria das espécies domésticas a diferenciação das células de Leydig fetal é provavelmente dependente da diferenciação das células de Sertoli (Kaminski et al., 1999).

Os espermatozoides se formam nos túbulos seminíferos pelo processo de espermatogênese, que se dá através da dinâmica de diferenciação das células germinativas, distribuídas na periferia dos túbulos seminíferos, migrando e se diferenciando no sentido da periferia para o lúmen (Kudryavtsev et al., 2003).

As espécies domésticas ao longo do seu desenvolvimento ultrapassam barreiras endócrinas que refletem sobre as características corporais. Assim dado os fenômenos da puberdade e maturidade sexual, o uso da biometria e da histometria testicular tem permitido avaliar características preditivas para seleção 
de reprodutores (Engelking, 2010). O diâmetro do túbulo seminífero é um parâmetro que pode ser abordado como indicador da atividade espermatogênica em avaliações com objetivos experimentais e análises toxicológicas (Assis-Neto et al., 2003).

O volume do parênquima testicular de mamíferos é bastante variável, sendo um dos principais fatores responsáveis pela diferença observada na eficiência da produção espermática nas diversas espécies (França \& Godinho, 2003).

A mensuração do peso testicular compreende método de avaliação indireta do desenvolvimento reprodutivo, enquanto a quantificação do epitélio seminífero representa um método direto de avaliar o estágio reprodutivo dos machos (Viu et al., 2006).

\section{Características testiculares nas diferentes espécies domésticas}

As características testiculares diferem de acordo com a espécie animal, quer seja na posição, morfologia ou biometria. Parâmetros como tamanho testicular podem variar ao longo do ano em animal de reprodução sazonal (Hafez \& Hafez, 2004). Em gatos, porco e lhama os testículos localizam-se posteriormente em relação ao corpo do animal, nos ruminantes os testículos são pendulares e ventrais, perpendicular, os do cão e equino são posicionados mais horizontalmente (Dukes et al., 2006). Alguns animais, como caprinos nativos, apresentam mais uma variável na manutenção do controle da termorregulação, que pode ser observada através de características como escrotos bipartidos, no qual é possível acomodar os testículos em cada escroto (Robertshaw, 1982), proporcionando uma maior aeração e, consequentemente, melhor qualidade seminal, o que pode resultar em uma maior taxa de fertilidade (Fatet et al., 2011; Nunes \& Salgueiro, 2011). Em zebuínos da raça nelore, a morfologia do escroto e dos testículos de alguns animais apresenta-se diferenciados das de taurinos, sugerindo estudados padrões de medidas testiculares adequados para os zebuínos. A parcial divisão do escroto de reprodutores zebuínos, de clima tropical e subtropical, sugere a ocorrência de seleção natural para proporcionar melhor termorregulação (Neves, 2007; Pinho et al., 2001).

Ademais, tem sido observado que animais menores tendem a apresentar maior proporção de massa corporal em testículos. Dentre as diferentes espécies, além do tamanho corporal, o índice gonadossomático é ainda influenciado por fatores como o sistema de acasalamento, freqüência de cópula e mesmo a duração do estro e mecanismo de ovulação (Kenagy \& Trombulak, 1986).

\section{Características morfométricas}

Fatores como efeito ambiental e mecanismos genéticos causam influência sobre o tamanho e a morfologia testicular, além de definir a morfologia do escroto como consequência da pressão exercida pelos testículos e por influência dos andrógenos, em ação combinada, por ocasião da descida testicular (Fatet et al., 2011; Nunes \& Salgueiro, 2011). Características relacionadas à biometria testicular como a circunferência escrotal, perímetro testicular, o volume testicular, e a forma testicular associada a qualidade seminal, têm sido medidas úteis na seleção de reprodutores (Silva et al., 2002; Unanian et al., 2000).

\section{Circunferência escrotal}

A busca por maiores valores de circunferência escrotal tem conduzido à seleção de formas testiculares mais ovaladas ou mesmo esféricas. Porém, a ocorrência da forma testicular alongada, característica de zebuínos, em particular na raça Nelore, em função da circunferência escrotal normalmente pequena, tem preocupado os criadores ao selecionarem os seus reprodutores. Isto se deve, aos critérios de seleção pelo tamanho da circunferência escrotal, em que machos com testículos longos podem ser eliminados por apresentarem circunferências menores que os seus contemporâneos de testículos ovais (Silva et al., 2002; Unanian et al., 2000).

Segundo Costa \& Silva (1994) zebuínos possuem testículos mais longos que os taurinos, por esse motivo apresentam circunferência escrotal menores. Touros com idade mais avançada e tempo mais prolongado em atividade sexual apresentam maior circunferência escrotal com maior quantidade de parênquima testicular, aumentando o peso testicular (Bertol et al., 2015). 
Vale ressaltar que a circunferência escrotal nos bovinos pode variar entre raças e entre linhagens, numa mesma raça. Assim, entre quatro raças criadas no hemisfério norte (Aberdeen Angus, Holandês, Charolês e Santa Gertrudes), a Aberdeen Angus apresentou a maior circunferência escrotal aos 12 meses de idade $(34,8 \mathrm{~cm})$ e a raça Holandesa a menor $(31,7 \mathrm{~cm})$. Entretanto, com 36 meses de idade a situação se inverteu, onde a raça holandesa superou todas as demais com 39,3 cm (Morrow, 1980). Entre os grupamentos genéticos de zebuínos criados no Brasil, aos 36 meses de idade, as circunferências escrotais foram as seguintes: Gir 34,73 $\pm 3,2 \mathrm{~cm}$; Nelore Mocho, 35,32 $\pm 3,3 \mathrm{~cm}$; Nelore, 35,35 \pm 2,7 cm; Gir Mocho 36,27 $\pm 1,5 \mathrm{~cm}$; Guzerá 37,21 $\pm 5,6 \mathrm{~cm}$; Tabapuã, 39,61 $\pm 5,1 \mathrm{~cm}$; Indubrasil, 43,58 $\pm 5,2 \mathrm{~cm}$ (Neves, 2007; Pinho et al., 2001; Pinto et al., 1989).

No entanto, vários fatores afetam os valores da circunferência escrotal e, consequentemente, a qualidade do sêmen, dentre os quais: idade, peso, ano e época de obtenção da medida (Boligon et al., 2007; Menegassi et al., 2011; Pereira et al., 2000; Pineda et al., 2000). Dessa forma, para oferecer subsídios seguros sobre o potencial reprodutivo do animal, além da circunferência escrotal, deve-se proceder a uma investigação do histórico, realizar o exame clínico geral, fazer o exame físico dos órgãos genitais internos e externos, observar o comportamento sexual e coleta e avaliação da qualidade do sêmen (Pinto et al., 1989).

\section{Perímetro escrotal}

Dentre os parâmetros biométricos, o perímetro escrotal, é uma medida que apresenta alta repetibilidade, caracterizada por possuir herdabilidade de moderada a alta (Viu et al., 2006). Esta medida apresenta grande importância, uma vez que se correlaciona com o ganho de peso, e características reprodutivas tanto da fêmea, como: idade ao primeiro parto, probabilidade de prenhez, número de dias para o parto e intervalo entre partos; quanto do macho, como: volume testicular, formato testicular e defeitos espermáticos (Pereira et al., 2000; Siqueira et al., 2013). O perímetro escrotal é um marcador adequado para presumir a precocidade sexual, mas não a fertilidade e a qualidade genética do animal (Lima et al., 2011).

O crescimento corporal e o desenvolvimento testicular têm forte relação entre si, no qual o crescimento do perímetro escrotal apresenta comportamento curvilíneo em função da idade (Boligon et al., 2010). Os testículos crescem, inicialmente lento, acelerando seu crescimento na fase puberal, com posterior decréscimo na velocidade de crescimento até a fase adulta (Bourdon \& Brinks, 1986).

Como parâmetro para programas de melhoramento genético recomenda-se a mensuração do perímetro escrotal feita antes da idade da puberdade e quanto maior a idade do animal maior será a herdabilidade. Em zebuínos e taurinos a variação na época da mensuração do perímetro escrotal tende a ocorrer devido à diferença da idade a puberdade entre os dois.

\section{Comprimento testicular}

O tamanho dos testículos é uma característica importante de média a alta hereditariedade que fornece uma estimativa precisa da quantidade de parênquima produtor de espermatozoides (Cunningham, 2011). A espermatogênese é um evento que ocorre mediante interação entre o sistema endócrino, sob atuação hormonal em especial das gonadotrofinas e mais intimamente dos hormônios esteroidais como a testosterona, além da competência celular das células somáticas.

As sertoli povoam a periferia dos túbulos seminíferos e são responsáveis por toda a espermatogênese. Assim quanto maior a quantidade de células de sertoli presente nos túmulos seminíferos maiores a produção espermática. As variações no comprimento testicular são bem observadas nas diversas espécies domésticas, o que consequentemente promove alteração na produção diária de sêmen entre espécies.

Testículos mais longos demonstram melhor adaptabilidade às regiões tropicais, e mesmo podendo apresentar menor perímetro escrotal, apresentam volumes semelhantes às demais formas sendo apontados como favoráveis à reprodução, principalmente, considerando-se as condições de temperatura elevada em que são criados os zebuínos (Bailey et al., 1996). 


\section{Volume testicular}

A avaliação da biometria testicular traz informações importantes no que tange a seleção de machos reprodutores, podendo ser realizado por meio da ultrassonografia. Em touros Zebuínos, o volume testicular seria a característica indicadora mais adequada na seleção para precocidade sexual e desempenho reprodutivo de fêmeas e machos (Pereira et al., 2000; Pineda et al., 2000; Siqueira et al., 2013). O volume testicular pode-se apresentar bem variável, principalmente, entre a fase pré-puberal e a fase adulta, dos 12 aos 20 a 24 meses de idade, em animais Brahman, o crescimento testicular ocorre de forma muito rápida e, quando alcançam 24 meses, os seus tamanhos assemelham-se aos dos machos taurinos. Além disso, a correlação observada entre a circunferência escrotal e o volume testicular aos 12 e 18 meses de idade em touros, mostra a possibilidade de se avaliar e predizer o potencial reprodutivo, por ocasião da seleção de machos para reprodutores, utilizando-se qualquer um destes parâmetros (Silva et al., 2002; Unanian et al., 2000).

\section{Considerações finais}

A população animal brasileira apresenta grande diversidade genética, o que possibilita alto diferencial de seleção, com grande potencial de ganho genético. A relação genética e os parâmetros biométricos juntamente com valores da avaliação seminal, tem sido favorável na escolha e seleção de bons reprodutores. A seleção pelo perímetro escrotal correlaciona-se a algumas características reprodutivas de machos e fêmeas, e características ponderais, devido a sua alta herdabilidade. No entanto, não se deve ser considerada isoladamente nos programas de melhoramento genético.

\section{Referências bibliográficas}

Assis-Neto, A. C., Carvalho, M. A. M., Melo, M. I. V., Miglino, M. A., Oliveira, M. F. \& Mariana, A. N. B. (2003). Fases do desenvolvimento e diferenciação testicular em cutias (Dasyprocta aguti) criadas em cativeiros. Brazilian Journal of Veterinary Research and Animal Science, 4071-79.

Bailey, T. L., Monke, D., Hudson, R. S., Wolfe, D. F., Carson, R. L. \& Riddell, M. G. (1996). Testicular shape and its relationship to sperm production in mature Holstein bulls. Theriogenology, 46(5):881887.

Bertol, M. A. F., Weiss, R. R., Kozicki, L. E. \& Abreu, A. C. M. R. (2015). Características biométricas e parâmetros espermáticos de testículos e epidídimos direitos e esquerdos de touros zebuínos. Archives of Veterinary Science, 20(2):156-163.

Boligon, A. A., Rorato, P. R. N. \& Albuquerque, L. (2007). Correlações genéticas entre medidas de perímetro escrotal e características produtivas e reprodutivas de fêmeas da raça Nelore. Revista Brasileira de Zootecnia, 36(3):565-571.

Boligon, A. A., Silva, J. A. V., Sesana, R. C., Sesana, J. C., Junqueira, J. B. \& Albuquerque, L. G. (2010). Estimation of genetic parameters for body weights, scrotal circumference, and testicular volume measured at different ages in Nellore cattle. Journal of Animal Science, 88(4):1215-1219.

Bourdon, R. M. \& Brinks, J. S. (1986). Scrotal circunference in yearling Hereford bulls: adjustment factors, herdabilities and genetic, environmental and phenotypic relationships with growth traits. Journal of Animal Science, 62958-967.

Combes, A. N., Wilhelm, D., Davidson, T., Dejana, E., Harley, V., Sinclair, A. \& Koopman, P. E. c. m. d. t. c. f. D. o. B., 112-20. (2009). Development of Biology. 326(112-120).

Costa e Silva, V. E. (1994). Avaliação da capacidade reprodutiva de touros Nelore. Exame andrológico, teste de comportamento sexual e desafio da fertilidade. Master of Science, Universidade Federal de Minas Gerais, Belo Horizonte, Minas Gerais, Brasil.

Cunningham, J. (2011). Tratado de fisiologia veterinária. Rio de Janeiro: Guanabara Koogan.

Dukes, H. H., Reece, W. O., Figueiredo, C., Vanzellotti, I. R. \& Zanon, R. F. (2006). Fisiologia dos animais domésticos (Vol. 1): Guanabara Koogan.

Engelking, L. (2010). Fisiologia endócrina e metabólica em medicina veterinária. São Paulo, Brasil: Roca. 
Fatet, A., Pellicer-Rubio, M.-T. \& Leboeuf, B. (2011). Reproductive cycle of goats. Animal Reproduction Science, 124(3-4):211-219. doi: http://dx.doi.org/10.1016/j.anireprosci.2010.08.029

França, L. R. \& Godinho, C. C. (2003). Testis morphometry seminiferous ephitelium cycle lenght and daily sperm production in domestic cats. Biology of Reproduction, 681554-1561.

França, L. R., Silva, V. A., Chiarini-Garcia, H., Garcia, S. K. \& Debeljuk, L. (2000). Cell proliferation and hormonal changes during postnatal development of the testis in the pig. Biology of Reproduction, 631629-1636.

Genovese, P., Nuñez, M. E., Pombo, C. \& Bielli, A. (2010). Undernutrition during foetal and post-natal life affects testicular structure and reduces the number of Sertoli cells in the adult rat. Reproduction in Domestic Animals, 45(2):233-236.

Godfrey, R. W., Lunstra, D. D., Jenkins, T. G., Berardinelli, J. G., Neuendorff, D. A., Long, C. R. \& Randel, R. D. (1990). Effect of location and season on body and testicular growth in Brahman and Hereford bulls. Journal Animal Science, 681520-1529.

Hafez, B. \& Hafez, E. (2004). Reprodução Animal (Vol. 1, pp. 513): Manole: São Paulo, Brasil.

Hutson, J. M., Li, R., Southwell, B. R., Newgreen, D. \& Cousinery, M. (2015). Regulation of testicular descent. Pediatric Surgery International, 31317-325.

Hutson, J. M., Southwell, B. R., Li, R., Lie, G., Ismail, K., Harisis, G. \& Chen, N. (2013). The regulation of testicular descent and the effects of cryptorchidism. Endocrine of Review, 34(5):725-752.

Kaminski, M. A., Corbin, C. J. \& Conley, A. J. (1999). Development and differentiation of the interstitial and tubular compartments of fetal porcine testes. Biology of Reproduction, 60119-127.

Kastelic, J. P., Cook, R. B. \& Coulter, G. H. (1997). Contribution of the scrotum, testes, and testicular artery to scrotal/testicular thermoregulation in bulls at two ambient temperatures. Animal Reproduction Science, 45(4):255-261.

Kenagy, G. J. \& Trombulak, S. C. (1986). Size and function of mammalian testes in relation to body size. Journal Mammalian, 671-22.

Kolb, E. (1984). Fisiologia veterinária. Rio de Janeiro: Koogan.

Köning, H. E. \& Liebich, H. G. (2011). Anatomia dos animais domésticos texto e atlas colorido. Porto Alegre, Rio Grande do Sul, Brasil: Editora Artmed.

Kudryavtsev, I. V., Safronova, L. D. \& Kudryavtsev, P. I. (2003). Genetic control of spermatogenesis and sex determination in mammals. Russian Journal of Developmental Biology, 34337-346.

Lima, F. P. C., Bergmann, J. A. G., Xavier, P. R. \& Marques Júnior., A. P. (2011). Características zootécnicas de touros da raça Nelore submetidos a um programa de seleção para precocidade sexual. Arquivo Brasileiro de Medicina Veterinária e Zootecnia, 63(6):1303-1308.

Menegassi, S. R., Barcellos, J. O., Peripolli, V., Pereira, P. R. R., Borges, J. B. \& Lampert, V. N. (2011). Determinação da circunferência escrotal em touros de corte no Rio Grande do Sul. Arquivo Brasileiro de Medecina Veterinária e Zootecnia, 63(1):87-93.

Morrow, D. A. (1980). Current therapy in theriogenology: diagnosis, treatment, and prevention of reproductive diseases in animals. Philadelphia, USA: Saunders.

Murta, D. V. F., Murta, D. C. R. X., Souza, R. B., Araújo, C. F., Barbosa, L. K. G., Santos, J. M. L., . . . Alves, R. G. N. (2019). A organização dos testículos. PUBVET, 13(7):1-6.

Neves, A. L. A. (2007). Biometria e morfologia testicular em bovinos da raça Nelore criados a pasto. Master of Science, Universidade Estadual do Sudoeste da Bahia, Itapetinga.

Nunes, J. F. \& Salgueiro, C. C. M. (2011). Strategies to improve the reproductive efficiency of goats in Brazil. Small Ruminant Research, 98(1-3):176-184. doi: http://dx.doi.org/10.1016/j.smallrumres.2011.03.036

O'donnel, L., Robertson, K. M., Jones, M. E. \& Simpson, E. R. (2001). Estrogen and spermatogenesis. Endocrine Reviews, 22(3):289-318.

Pereira, E., Eler, J. P. \& Ferraz, J. B. S. (2000). Correlação genética entre perímetro escrotal e algumas características reprodutivas na raça Nelore. Revista Brasileira de Zootecnia, 29(6):1676-1683. 
Pineda, N. R., Fonseca, V. O. \& Albuquerque, L. G. (2000). Estudo preliminar da influência do perímetro escrotal sobre a libido em touros jovens da raça Nelore. Arquivo Brasileiro de Medicina Veterinaria e Zootecnia, 52(1):69-75.

Pinho, T. G., Nogueira, L. A. G., Pinto, P. A., Zamborlini, L., Gilardi, S., Caldas, M. \& Souza, R. M. (2001). Características seminais de touros jovens nelore (Bos taurus indicus) de acordo com a biometria e morfologia testicular. Revista Brasileira Reprodução Animal, 25(2):187-189.

Pinto, P. A., Silva, P. R., Albuquerque, L. G. \& Bezerra, L. A. F. (1989). Avaliação da biometria testicular e capacidade de monta em bovinos das raças Guzerá e nelore. Revista Brasileira de Reprodução Animal, 13151-156.

Quirino, C. R. \& Bergmann, J. A. G. (1999). Heritability of scrotal circumference adjusted and unadjusted for body weight in Nellore bulls using ani and bivariate animal models. Theriogenology, 48(7):1389-1396.

Robertshaw, D. (1982). Concepts in animal adaptation: Thermoregulation of the goat. Dairy Goat Journal, 1395-397.

Silva, A. E. D. F., Dode, M. A., Porto, J. A. \& Abreu, U. G. P. (1991). Estacionalidade na atividade sexual de machos Nelore e mestiços Fleckvieh e Chianina x Nelore: características biométricas testiculares. Pesquisa Agropecuária Brasileira, 26(10):1745-1750.

Silva, A. E. D. F., Unanian, M. M., Cordeiro, C. M. T. \& Freitas, A. R. (2002). Relação da circunferência escrotal e parâmetros da qualidade do sêmen em touros da raça Nelore, PO. Revista Brasileira de Zootecnia, 31(3):1157-1165.

Siqueira, J. B., Guimarães, J. D. \& Pinho, R. O. (2013). Relação entre perímetro escrotal e características produtivas e reprodutivas em bovinos de corte: uma revisão. Revista Brasileira de Reprodução Animal, 37(1):3-13.

Sisson, S., Grossman, J. D. \& Getty, R. (1986). Anatomia dos animais domésticos. Rio de Janeiro: Interamericana.

Skakkebaek, N. E., Rajpert-De Meyts, E., Buck Louis, G. M., Toppari, J., Andersson, A. M. \& Eisenberg, M. L. (2016). Male reproductive disorders and fertility trends: influences of environment and genetic susceptibility. Physiological Reviews, 96(1):55-97.

Unanian, M. M., Silva, A. E. D. F., Pimentel, C. M. M. \& Cardoso, E. P. (2000). Características biométricas testiculares para avaliação de touros zebuínos da raça Nelore. Revista Brasileira de Zootecnia, 29136-144.

Vásquez, L., Vera, O. \& Arango, J. (2003). Testicular growth and semen quality in peripuberal Brahman bulls. Livestock Research for Rural Development, 15(10):1-6.

Virtanen, H. E. \& Adamsson, A. (2012). Cryptorchidism and endocrine disrupting chemicals. Molecular and Cellular Endocrinology, 355208-220.

Viu, M., Magnabosco, C., Ferraz, H., Gambarini, M., Oliveira Filho, B., Lopes, D. \& Viu, A. (2006). Desenvolvimento ponderal, biometria testicular e qualidade seminal de touros Nelore (Bos taurus indicus) criados extensivamente na região centro-oeste do Brasil. Archives of Veterinary Science, 11(3):53-57.

Zambrano, E., Rodrigez-González, G. L., Guzmán, C., García-Becerra, R., Boeck, L., Díaz, L., . . . Nathanielsz, P. W. (2005). A maternal low protein diet during pregnancy and lactation in the rat impairs male reproductive development. Journal of Physiology, 563275-284.

Recebido: 4 setembro, 2019.

Aprovado: 8 de novembro, 2019.

Publicado: 24 de janeiro, 2020.

Licenciamento: Este artigo é publicado na modalidade Acesso Aberto sob a licença Creative Commons Atribuição 4.0 (CC-BY 4.0), a qual permite uso irrestrito, distribuição, reprodução em qualquer meio, desde que o autor e a fonte sejam devidamente creditados. 